(RESEARCH ARTICLE)

\title{
Finding of microorganisms in patients with cervicovaginal polyps
}

\author{
Guillermo Muñoz Zurita 1, * , José Antonio Sánchez Hernández 2 and David Castillo Flores 2 \\ ${ }^{1}$ Departamento de Farmacología Facultad de Medicina, Benemérita Universidad Autónoma de Puebla, Puebla, Puebla, \\ México. \\ ${ }^{2}$ Departamento de Biología Celular Facultad de Medicina, Benemérita Universidad Autónoma de Puebla, Puebla, Puebla, \\ México.
}

Publication history: Received on 17 October 2020; revised on 26 October 2020; accepted on 28 October 2020

Article DOI: https://doi.org/10.30574/wjarr.2020.8.1.0391

\begin{abstract}
Introduction: the variation of microorganisms of the vaginal canal is reported in patients with the presence of modified cervicovaginal polyps from the city of Puebla, Mexico; describing the vaginal microbiota and pathogenic microorganisms in order to analyze the possible association of these with the formation of cervicovaginal polyps.

Methods: the clinical impressions and samples obtained from the patients who attended the Department of Cell Biology of the Faculty of Medicine of the Benemérita Universidad Autónoma de Puebla were analyzed within the framework of the Early Cancer Detection (DOC) program of the years 2001 to 2019, to the taking of cervicovaginal exfoliative cytology (PAP).

Results: Of the 2,671 patients who met the inclusion criteria when presenting with cervicovaginal polyp, $82.14 \%$ reported the presence of microorganisms, being cocoid flora, the most frequent microorganism found in patients with cervicovaginal polyps, thus, the need for more studies deep and extensive in Mexico, due to the null reviews reported in the scientific literature.
\end{abstract}

Keywords: Cervicovaginal polyps; microorganisms; cervicovaginal exfoliative cytology; vaginal microbiota

\section{Introduction}

Deaths caused by diseases of the female genital tract increasingly affect the health of the entire world. Due to this, the need arises to perform annual reviews in patients with active sexual life for the early detection of any abnormality, thus, cervicovaginal polyps one of the most common lesions found in women of reproductive age with a fairly uncertain epidemiology and pathogenesis. ${ }^{1,2}$

The human body harbor microbial ecological communities that are in a mutualist relation with the host and they inhabit surfaces and cavities in each sites of the body. ${ }^{3}$ One that stands out is the vaginal ecosystem, made up of a microbiota that protects against pathogenic microorganisms involved in reproductive health and disease. While many factors, including ethnicity, diet, and cultural background, affect the vaginal microbiota predominantly due to the diversity of Lactobacillus species.4-7

In this way, the vaginal environment is kept in balance due to the predominant action of Lactobacillus that maintain the acid $\mathrm{pH}$ in the vagina, and by generating an imbalance in the microenvironment, the protective effect on the integrity of the epithelial barrier decreases, causing vaginal infections of internal and external origin caused by bacterial, fungal,

\footnotetext{
${ }^{*}$ Corresponding author: Guillermo Muñoz Zurita

Departamento de Farmacología Facultad de Medicina, Benemérita Universidad Autónoma de Puebla, Puebla, Puebla, México. 
protozoan microorganisms and viruses, such as: Gardnerella vaginalis, Leptothrix actinomyces, Candida albicans and human papillomavirus (HPV). ${ }^{7-9}$

It should be noted that Lactobacillus are key protective species of the vaginal mucosa that include $70 \%$ of the total population of the vaginal microenvironment in healthy women, express specific adhesion to surface epithelial cells, and also produce antimicrobial substances such as organic acids, peroxide hydrogen, bacteriocins and surfactants, thus hindering the establishment of pathogenic microorganisms. ${ }^{8-10}$ With the advent of classification by molecular methods (fundamentally the analysis of the amplicon sequence of the 16S rRNA gene), it has been observed that there are approximately 45 species of Lactobacillus predominant in the vagina, with the greatest proportion being: Lactobacillus acidophilus, L.crispatus, L.iners, L.jensenii, L. gasseri, L. salivarius and L.vaginalis, all of them important for the maintenance of one of the most important microbiological communities of the body such as the vaginal microbiota. ${ }^{3,11}$

This investigation is detailed as follows:

Section 1: Introduction on the subject of vaginal microbiota and cervicovaginal polyps.

Section 2: Description of the materials and methods used to obtain samples.

Section 3: Analysis of results and partial conclusions and discussion of the topic.

\section{Material and methods}

Cross-sectional, descriptive and observational study in which the clinical impressions and samples obtained from the patients who attended the Department of Cell Biology of the Faculty of Medicine of BUAP, to the cervicovaginal exfoliative cytology (PAP) taken in the framework of the DOC program, from the years 2001 to 2019. The samples obtained were fixed and stained with the modified Papanicolaou staining train and subsequently mounted with synthetic resin for their microscopic interpretation.

It was included patients in the study of female genitalia who manifested cervicovaginal polyp, in addition to the following inclusion and exclusion criteria:

- Inclusion criteria: patients who have started their active sexual life and who did not have in their menstrual period during the taking.

- Exclusion criteria: virgin, pregnant patients, patients in their menstrual period and patients who do not have a cervicovaginal polyp at clinical impression.

\section{Results and discussion}

After reviewing the samples of the patients who manifested cervicovaginal polyps, the presence of various microorganisms was found, which are presented in Table 1.

Table 1 Pathogenic and vaginal microbiota

\begin{tabular}{|l|l|}
\hline Microorganisms & Percentages and number of patients \\
\hline Cocoid flora and Lactobacillus & $4(14.28 \%)$ \\
\hline Cocoid flora & $14(50 \%)$ \\
\hline Cocoid flora and HPV & $1(3.57 \%)$ \\
\hline Cocoid flora and Candida albicans & $1(3.57 \%)$ \\
\hline Cocoid flora and Leptothrix actinomyces & $2(7.14 \%)$ \\
\hline Cocoid flora and Gardnerella vaginalis & $1(3.57 \%)$ \\
\hline No presence of microorganisms & $5(17.85 \%)$ \\
\hline TOTAL & $28(100 \%)$ \\
\hline \multicolumn{2}{|c|}{ Microorganisms found in patients with polyps. }
\end{tabular}

Of the 2,671 patients registered in our database, 28 met the inclusion criteria when presenting with cervicovaginal polyp; Of these, 23 reported the presence of a microorganism at cytodiagnosis, that is, $82.14 \%$ of the patients with cervicovaginal polyp, with the most frequent microorganism found in patients with polyps being cocoid flora (Photograph 1). 


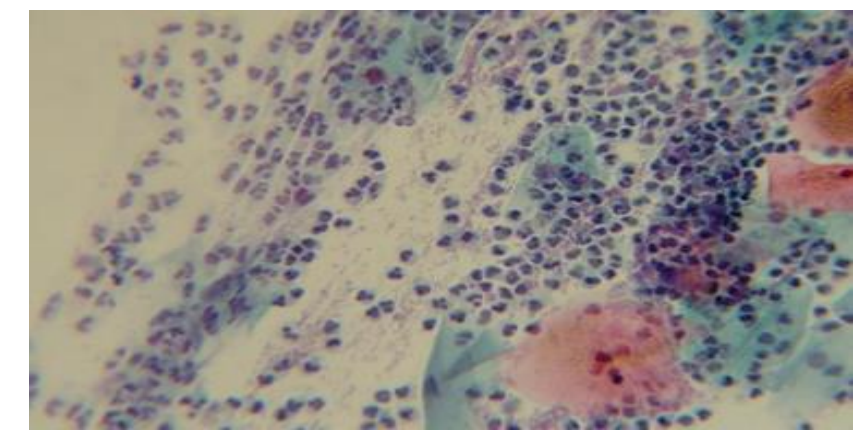

Photograph 1 Cocoid flora and Leucocytes (40x)

Likewise, it was reported that 5 patients, corresponding to $17.85 \%$, presented clinically confirmed cervicovaginal infection and cytodiagnosis (morphological finding of HPV, Candida albicans, Gardnerella vaginalis, Leptothrix actinomyces) in concomitance with the presence of cervicovaginal polyps. On the other hand, 18 patients, corresponding to $64.28 \%$, revealed a normal vaginal microbiota at cytodiagnosis (cocoid flora and Lactobacillus) and the presence of cervicovaginal polyp. While 5 patients $(17.85 \%)$ did not report any microorganism to the cytodiagnosis; these data are presented in Figure 1.

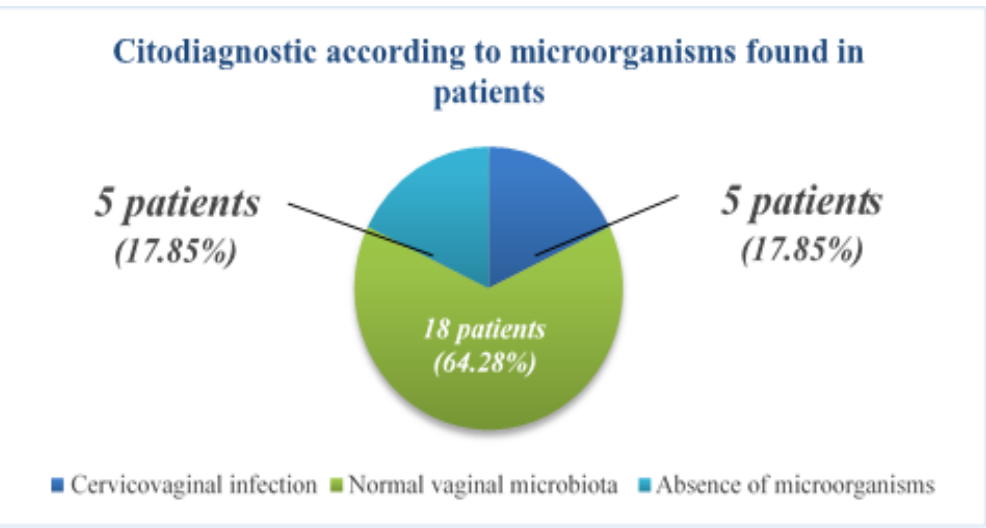

Figure 1 Citodiagnostic according to microorganisms found in patients.

In addition, of the 23 patients who presented some microorganism, we appreciate that 9 showed mixed flora (39.13\%), that is, that they do not harbor a single microorganism but there is the presence of more than one of these, while in 14 patients was found cocoid flora as the only microorganism in our patients (60.86\%), data presented in Figure 2.

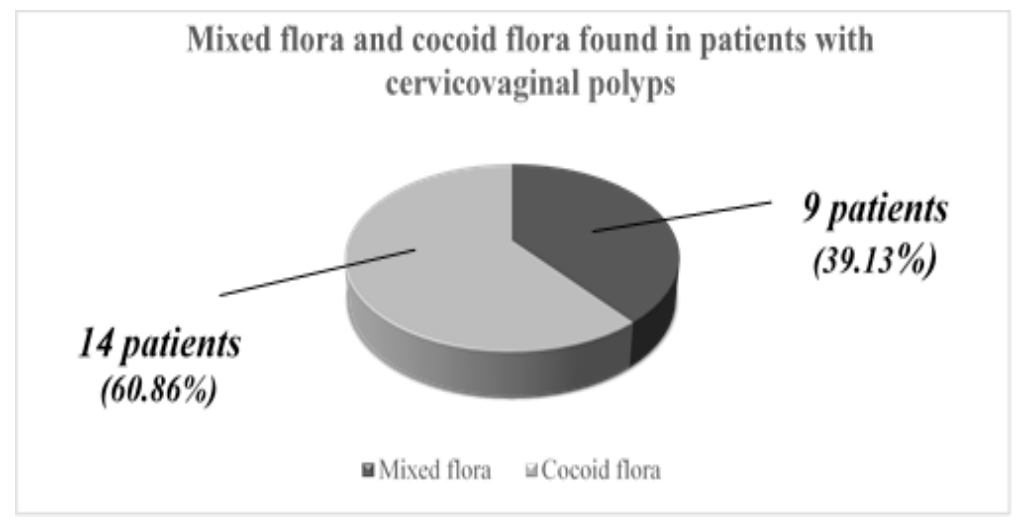

Figure 2 Mixed flora and cocoid flora found in patients with cervicovaginal polyps. 


\section{Discussion}

According to the bibliographies consulted, we know much of the etiology of the microorganisms already mentioned and the various clinical entities that cause them; such is the case of Gardnerella vaginalis, which depletes the Lactobacillus population and encourages the proliferation of anaerobic microorganisms, aminated odor, and increased vaginal discharge and pH (Photographs 2 and 3); Candida albicans, which due to the adherence of proteolytic enzymes causes erythema, pruritus, dysuria and vaginal discharge with a lumpy consistency (Photo 5); HPV, which causes low-grade intraepithelial injury and koilocyte formation thanks to the expression of proteins that penetrate the cervical basal layer (Photo 6) and Actinomyces species, for which there are few studies that provide information on their prevalence (Photo 4). $4,11-14$

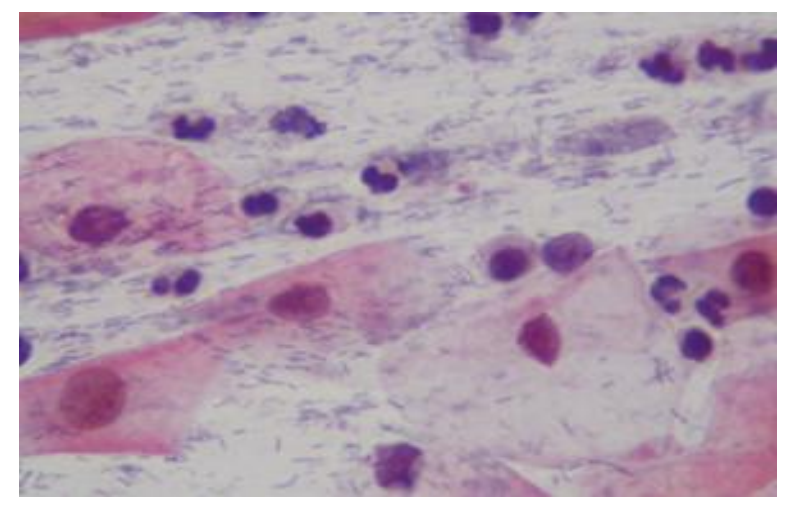

Photograph 2. Lactobacillus spp. (100x)

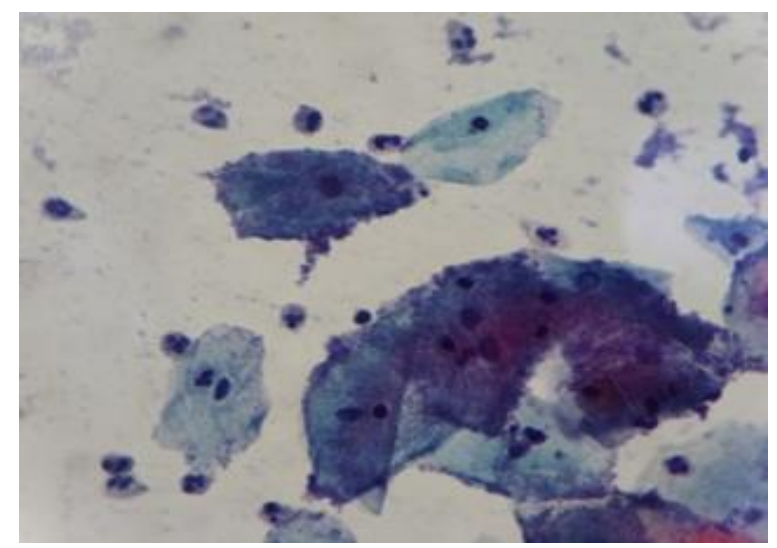

Photograph 3. “Clue cells” by Gardnerella vaginalis (40x)

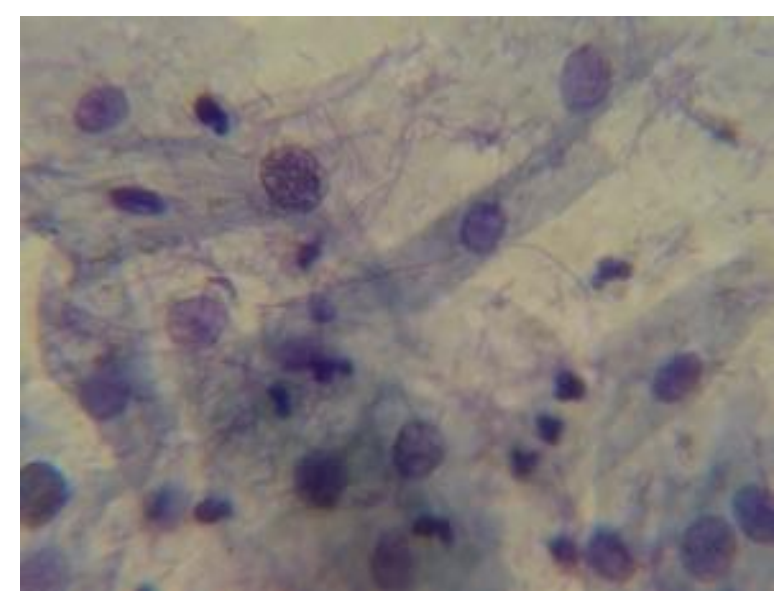

Photograph 4. Leptothrix actinomyces 


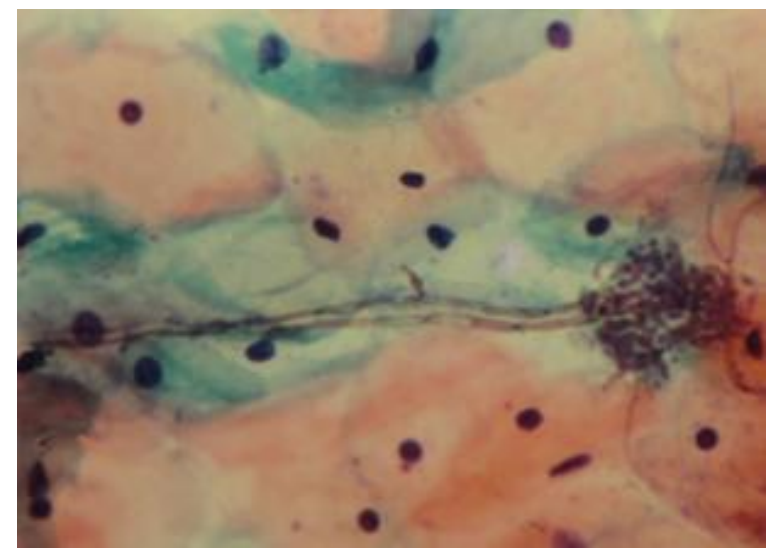

\section{Photograph 5 Candida spp. (40x) (40x)}

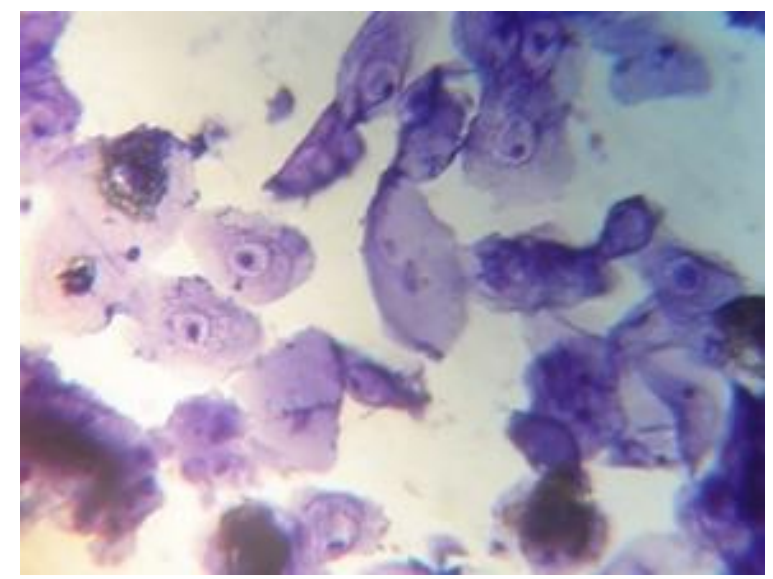

Photograph 6 Coilocytes by HPV (40x)

Based on the foregoing, the theory is reached that said microorganisms could affect the place of proliferation of a polyp by some mechanism not yet known, thus highlighting the presence of important clinical manifestations found during the performance of cervicovaginal exfoliative cytology. , such as: erosion, leucorrhea, vulvar itching, bleeding at intercourse and dyspareunia, as well as results reported in the interrogations and gynecological impressions of the patients, highlighting changes in the $\mathrm{pH}$ and alteration of the integrity of the vaginal epithelium; thus, the microorganisms of the vaginal canal are involved in the formation of cervicovaginal polyps, with histological and cellular modifications, as well as chronic infections, being responsible for said appearance.

However, we must prioritize the clinical manifestations and the establishment of microorganisms are attributed to specific cervicovaginal infections and normal vaginal microbiota. ${ }^{4,7-9}$ Thus, these microorganisms are not related to the formation of polyps, since the finding of these in the samples analyzed is a sporadic discovery and the formation of cervicovaginal polyps is attributed to other well-known independent causes and mechanisms, such as : proliferative processes, vascular neoformations, hormonal factors (hyperestrogenic), genetic modifications, chronic inflammatory phenomena, stromal hyper cellularity, cytological atypia, increased mitosis, hyperplasia of the glandular and endometrial epithelium; as well as aging, insulin resistance, obesity, high blood pressure, postmenopausal period, smoking and tamoxifen use. ${ }^{15-17}$.

\section{Conclusion}

After analyzing the results and studying the colonization mechanisms of the microorganisms found in our patients, the presence of these is concluded, they are a fortuitous finding due to the null cases reported in the literature; The routes by which these microorganisms are defined in the vaginal canal are currently known, so the scope of this search shows that there is no direct association with the formation of cervicovaginal polyps, which is why it is indicated in the development of this investigation. 


\section{Compliance with ethical standards}

\section{Disclosure of conflict of interest}

The authors have no competing interests to declare.

\section{References}

[1] Soyer T, Demirdag G, Gücer S, Orhan D, Karnak I. Giant cervical polyp with mesonephric duct remnants: unusual cause of vaginal bleeding in an adolescent girl. Fetal Pediatr Pathol. 2014 Jun; 33(3):176-181.

[2] Tanos V, Berrey KE, Seikkula J, et al. The management of polyps in female reproductive organs. Int J Surg. 2017; 43:7-16.

[3] Pacha-Herrera D, Vasco G, Cruz-Betancourt C, Galarza JM, Barragán V, Machado A. Vaginal Microbiota Evaluation and Lactobacilli Quantification by qPCR in Pregnant and Non-pregnant Women: A Pilot Study. Front Cell Infect Microbiol. 2020 Jun; 19; 10:303.

[4] Nami Y, Haghshenas B, Yari Khosroushahi A. Molecular Identification and Probiotic Potential Characterization of Lactic Acid Bacteria Isolated from Human Vaginal Microbiota. Adv Pharm Bull. 2018 Nov; 8 (4):683-695.

[5] Álvarez-Calatayud G, Suárez E, Rodríguez JM, Pérez-Moreno J. La microbiota en la mujer; aplicaciones clínicas de los probióticos. Nutr Hosp. 2015; 32 [Supl.1]: 56-61.

[6] Guevara Armando, Santiago Verónica, Domínguez Anggie. Vaginosis citolítica: una entidad clínica poco conocida. Rev Obstet Ginecol Venez. 2011 Mar; 71(1):45-48.

[7] Sánchez HJA, Mayta BMJ, Pérez TR, et al. Descripción de la flora vaginal en mujeres histerectomizadas. Enf Infec Microbiol. 2012; 32(3):104-107.

[8] Ravel J, Gajer P, Abdo Z, Schneider GM, Koenig SS, McCulle SL, Karlebach S, Gorle R, Russell J, Tacket CO, Brotman RM, Davis CC, Ault K, Peralta L, Forney LJ. Vaginal microbiome of reproductive-age women. Proc Natl Acad Sci U S A. 2011 Mar 15; 108 Suppl 1:4680-4687.

[9] AI Kassaa I, Hamze M, Hober D, Chihib NE, Drider D. Identification of vaginal lactobacilli with potential probiotic properties isolated from women in North Lebanon. Microb Ecol. 2014 Apr; 67(3):722-734.

[10] Wessels JM, Lajoie J, Vitali D, Omollo K, Kimani J, Oyugi J, Cheruiyot J, Kimani M, Mungai JN, Akolo M, Stearns JC, Surrette MG, Fowke KR, Kaushic C. Association of high- risk sexual behaviour with diversity of the vaginal microbiota and abundance of Lactobacillus. PLoS One. 2017 Nov 2; 12 (11), e0187612.

[11] Oliveira et al. Vaginal microbial structure in BV and non-BV women. J Infect Dev Ctries. 2018; 12(2):127-136.

[12] García-García A, Coronel-Martínez J, Leon DC, Romero-Figueroa MDS, Caballero-Pantoja YE, Manzanares-Leal GL, Rodriguez-Morales M, Sandoval-Trujillo H, Ramírez-Durán N. Detection of Actinomyces spp. in cervical exudates from women with cervical intraepithelial neoplasia or cervical cancer. J Med Microbiol. 2017 Jun; 66(6):706-712.

[13] Pineda-Murillo J, et al. Candidosis vaginal: Revisión de la literatura y situación de México y otros países Latinoamericanos. Rev Med Risaralda. 2017 Jan; 23(1): 38 - 44.

[14] Alfaro CA, Fournier PM. Virus del papiloma humano. Rev Med Cos Cen. 2013; 70(606):211-217.

[15] Vivas CA, Ríos JJ, Romero HA. Pólipos endometriales, fisiopatología y factores de riesgo. Rev CES Med. 2012; 26(2):175-184.

[16] Villarreal-Ríos E, Benítez-Benítez S, Vargas-Daza ER, Martínez González L, Galicia-Rodríguez L, Escorcia-Reyes V. Incidencia de infecciones cervicovaginales diagnosticadas por citología y no tratadas médicamente. Ginecol Obstet Mex. 2018 marzo; 86(3):186-192.

[17] Sánchez-Hernández JA et al. Incidencia de pólipos cervicovaginales en pacientes con vida sexual activa. Rev Mex Patol Clin Med Lab. 2019; 66(3):139-142. 